\title{
A UTILIZAÇÃO DAS TICS E A CONTRIBUIÇÃO DAS CIDADES DIGITAIS PARA O FAVORECIMENTO DA GOVERNANÇA
}

\author{
THE USE OF ICT 'S AND THE CONTRIBUTION OF DIGITAL CITIES AS WAYS \\ TO ESTIMULATE GOVERNANCE
}

\author{
${ }^{1}$ Claudia Cecilia Camacho Rojas \\ ${ }^{2}$ Flavia Pitaki Dufour
}

\section{RESUMO}

No atual contexto da era da informação, as tecnologias de informação e comunicação (TICs) trazem novas possibilidades de interação entre os cidadãos e seus representantes. Considerando que as democracias contemporâneas vêm passando por uma crise de legitimidade, demanda-se do Poder Público e da própria sociedade a criação de novos espaços de comunicação e participação popular nas decisões políticas. Uma possibilidade que se tem considerado é o exercício de gestão através da governança, ou seja, uma forma mais horizontal de debate e decisão pública. Para implementar este ideal, pretende-se investigar se podem ser utilizadas as referidas TICs, dando ênfase para uma de suas formas, a cidade digital, estudando se sua criação pode vir a contribuir para o favorecimento da governança. Assim, iniciar-se-á trabalhando o conceito de governança contrastado com o de governo, para então tratar dos conceitos de governo eletrônico e governança eletrônica, comparando-os entre si. Em seguida, aprofundando brevemente o tema, serão expostas algumas contribuições acerca da internet, enquanto uma TIC, para o desenvolvimento da governança, para enfim investigar se a criação de cidades digitais pode vir a contribuir para o exercício da governança. Como metodologia, opta-se pelo método indutivo, realizado através da coleta de dados bibliográficos e decorrentes de outras pesquisas acadêmicas.

Palavras-chave: Governança, Governança eletrônica, Governo eletrônico, Tecnologia da informação e comunicação, Cidades digitais

\footnotetext{
${ }^{1}$ Mestranda em Direito pela Pontifícia Universidade Católica -PUC Curitiba, Paraná, (Brasil). Organizadora e Instrutora do Curso para Gestores de Contrato no Âmbito do Direito Administrativo, Realizado na Copel. E-mail: cccrojas@yahoo.com.br

${ }^{2}$ Mestranda em Direito pela Pontifícia Universidade Católica -PUC Curitiba, Paraná, (Brasil). Assessora Jurídica de Desembargador no TJ-PR, Brasil. E-mail: fpdufour@gmail.com
} 


\begin{abstract}
In the current context of the informational age, information and communication technologies (ICTs) provide new possibilities for interaction between citizens and their representatives. Considering that contemporary democracies are undergoing a crisis of legitimacy, there is a demand for the government and society to create new spaces of communication and popular participation in political decisions. One possibility that has been considered is to govern through governance, which implies a more horizontal form of public debate and decision. To implement this ideal, it is intended to investigate whether these ICTs can be used, giving emphasis to one of its forms, the digital city, studying whether its creation may ultimately contribute in favor of governance. So, we will start by working on the concept of governance contrasted with the concept of government itself, and then study e-government and e-governance concepts by comparing them with each other. Then, briefly reflecting on the theme, it will be exposed some contributions of the internet, as an ICT, for the development of governance, to finally investigate if the creation of digital cities can potentially contribute to the exercise of governance. The chosen methodology is the inductive method, conducted through the collection of bibliographic data and of data from other academic research.
\end{abstract}

Keywords: Governance, E-governance, E-government, Information and communication technology, Digital cities 


\section{INTRODUÇÃO}

A presente pesquisa parte de duas premissas, as quais serão retomadas no curso do artigo. Primeiramente, assume que, diante da atual situação das democracias contemporâneas, deve-se frisar o diálogo entre os cidadãos e os governantes a fim de recuperar a legitimidade democrática dos Estados e resgatar a cidadania dos indivíduos enquanto colaborador da comunidade política a que faz parte. Em segundo lugar, pressupõe que a sociedade atual inerentemente está dotada do adjetivo informacional, eis que inserida em um contexto de altas tecnologias de informação e comunicação (TIC's).

Várias são as possibilidades de favorecimento de participação política dos cidadãos nas decisões públicas, bem como muitas são as TIC's que podem ser utilizadas para os mais variados fins. Contudo, para fins deste estudo, opta-se por tratar da governança como alternativa complementar ao governo tradicional, entendendo ser esta uma forma de democratizar ainda mais as decisões políticas, da mesma forma como elenca as cidades digitais como TIC de investigação.

Nesta perspectiva, este artigo pretende estudar se podem ser utilizadas TIC's parafacilitar a governança, em especial investigando se as cidades digitais, enquanto TIC's, podem contribuir para tal fim, ou seja, se possibilitam uma maior participação política dos cidadãos nas questões de interesse público.

Para resolver tal problema, considerando a primeira premissa, iniciar-seá trabalhando o conceito de governança contrastado com o de governo.

Então, já incorporando a segunda premissa à pesquisa, se tratará dos conceitos de governo eletrônico e governança eletrônica, comparando-os entre si.

Aprofundando um pouco mais o tema, serão expostas algumas contribuições acerca da internet, enquanto uma TIC, para o desenvolvimento da governança.

Enfim, investigar-se-á se a criação de cidades digitais, enquanto TIC's que utilizam se manifestam por internet, pode vir a contribuir para o exercício da governança.

Para atingir tais objetivos, prima-se pelo método indutivo, realizado através da coleta de dados bibliográficos e decorrentes de outras pesquisas acadêmicas. 


\section{APRESENTANDO O CONCEITO DE GOVERNANÇA}

Inicialmente, pretende-se refletir sobre a necessidade de repensar mecanismos de participação do cidadão como forma de relegitimar o governo nas democracias atuais, apontando como uma possibilidade a ideia de governança. Assim, pretende-se conceitua-la a fim de criar parâmetros que devem permear a investigação final.

\subsection{A Crise de Governabilidade e a Necessidade de Relegitimar as Democracias Modernas}

Com a revolução democrática, o lugar do poder torna-se um "lugar vazio", o que impede os governantes de dele se apropriarem, de "se incorporarem no poder. Seu exercício depende do procedimento que permite um reajuste periódico” (LEFORT, 1991, p. 32).

A democracia, entendida como contraposta a qualquer forma de governo autocrático, rege-se por regras instituindo quais os procedimentos e quem são os responsáveis pelas decisões coletivas. Estas decisões, decorrentes de escolhas de determinado grupo social, são, por essência, tomadas por indivíduos enquanto participantes do coletivo (BOBBIO, 2000, p. 30-31).

Mais do que isso, a democracia, como compreendida por esta pesquisa, é naturalmente plural, e deve valorizar o conflito e o dissenso. Conforme a democracia agonística (de característica radical pluralista), identificada por Chantal Mouffe (1997, p. $11-$

20), deve-se sobressaltar o político e o mencionado dissenso, decorrente do pluralismo eminentemente característico da sociedade atual, devendo haver o reconhecimento e fortalecimento das múltiplas identidades inerentes aos indivíduos, percebendo no conflito e na diferença a natureza da própria democracia.

Contudo, os Estados democráticos, em especial o Brasil, têm manifestado uma crise de governabilidade $^{1}$, da qual decorre uma insatisfação da população com relação aos seus governantes, como se pôde verificar pelas notórias e intensas manifestações populares ocorridas recentemente, em especial aquelas de julho de 2013. 
Assim, deve-se primar pela confiança dos cidadãos na forma de governo eleita, através da ocupação de espaços públicos de comunicação e troca de informações com o governo, reforçando e recriando tanto as instituições quanto a autoridade governamental, razão pela qual cumpre à comunidade acadêmica sugerir novas formas de exercício de diálogoLegitimadoras da democracia.

\footnotetext{
1 Por governabilidade, se entende "a capacidade de um sistema político em produzir políticas públicas que resolvam os problemas da sociedade, ou a capacidade dos governos de converter o potencial político de um dado conjunto de instituições e práticas políticas em capacidade de definir, implementar e sustentar políticas" (MALLOY, 1993 apud SANTOS, 1997, p. 8).
}

\subsection{Governo X Governança}

A partir da demanda apontada, sugere-se a governança como forma de contribuir para a democracia. Diante das inúmeras utilizações do termo, cumpre inicialmente tratar de seu conceito, em especial relacionando-o com o conceito de governo.

Enquanto governo remete a atividades públicas geridas por uma autoridade formal, a qual utiliza o poder de polícia para implementas as políticas devidamente instituídas, governança é mais amplo, sugerindo que as atividades voltadas para o comum derivam tanto de instituições governamentais quanto de mecanismos informais, de caráter não governamental (ROSNEAU, 2000, p. 15-16).

A governança está no diálogo do governo com a sociedade no momento das escolhas públicas, na existência e ocupação de espaços públicos de debate e deliberação.

Para seu estímulo, “interessa, pois, explorar questões relativas a padrões de articulação e cooperação entre atores sociais e políticos e a arranjos institucionais que coordenam e regulam transações dentro e através das diversas fronteiras dos sistemas político e econômico". (AZEVEDO e ANASTASIA, 2002, p. 80).

$\mathrm{Na}$ governança, incluem-se não somente os tradicionais meios de agregação e articulação de interesses, como os partidos políticos, mas "também redes sociais informais (...), hierarquias e associações de diversos tipos” (SANTOS, 1996, p. 9)

Enquanto a governabilidade concerne "às condições sistêmicas sob as quais se dá o exercício do poder, ou seja, aos condicionantes do exercício da autoridade política, governança qualifica o modo de uso dessa autoridade”. Isso significa que a 
governança envolve, portanto, "além das questões político-institucionais de tomada de decisões, as formas de interlocução do Estado com os grupos organizados da sociedade, no que se refere ao processo de definição, acompanhamento e implementação de políticas públicas” (MELO, 1995; COELHO e DINIZ, 1995 apud AZEVEDO e ANASTASIA, 2002, p. 80).

Governança é uma palavra que tem origem na língua francesa. A evolução do seu significado está relacionada com as transformações históricas das civilizações que a empregavam, bem como com sua migração entre as diferentes regiões na Europa e no continente americano (CANET, 2004, p. 2-5).

Segundo o Programa das Nações Unidas para o Desenvolvimento — PNUD, a governança vai além de leis, regulamentos e instituições nacionais, embora sejam todos componentes muito importantes. Abrange também processos visando à promoção da participação da comunidade na tomada de decisões pertinentes, a uma mobilização social e aoutras ações que resultem em investimentos, capacitação e incentivos para a participação em um nível local (ONU, 2009, p. 1).

Todavia, a governança deve ser trabalhada com cautela:

“(...)a governança é um conceito pós-moderno, advindo deste novo ciclo de globalização em que vivemos. Ela possui características duais, que tanto pode servir para mascarar um processo de agudização da concentração de riquezas, como pode auxiliar os legítimos esforços das comunidades em aumentar sua capacidade de soberania e governabilidade local, agindo com prudência e respeito, e fazendo frente a atual onda avassaladora de homogeneização cultural e econômica. A idéia de governança surge no vazio de governabilidade provocado pela redução dos governos, resultado das exigências das políticas neoliberais e da aplicação do conceito de reengenharia aos processos públicos. Governança significa o aumento da capacidade de governar no nível local. Este aumento de governabilidade local está associado ao fenômeno da gestão compartilhada de interesses comuns, no qual a comunidade de interessados passa de consumidores a definidores e gestores políticos" (SILVA,

2006, p. 10).

Assim, para fins desta pesquisa, tem-se governança como o diálogo dos gestores públicos com os cidadãos e a comunidade, no sentido de conjugar esforços para a tomada 
das decisões políticas. Nesta toada, devem-se pensar formas de fortalecimento da governança, dentre as quais se sugere a utilização das TIC's.

\section{CONCEITUANDO E EXEMPLIFICANDO GOVERNO ELETRÔNICO E GOVERNANÇA ELETRÔNICA}

$\mathrm{Na}$ era de informação em que a humanidade se encontra, as tecnologias de informação e comunicação (TIC's) vem introduzindo uma nova forma de racionalização no setor público, a qual tem o condão de facilitar, inclusive, a administração das atividades pública (ONU, 2008, p. 2).

As tecnologias de informação e comunicação (TIC's) características desta nova eraestabeleceram uma ruptura com o status quo, impondo novos paradigmas. As tecnologias passaram a agir sobre a informação e, como esta integra toda a atividade humana, passaram também a permear as relações entre os indivíduos. Outro paradigma estabelecido, decorrente dos anteriores, afeta a forma como estas relações se manifestam: há uma nova lógica, em redes, a qual é mais flexível e integra as mais distintas partes do todo (CASTELLS, 2002, p.107-110).

Mesmo que as redes como forma de organização social tenham existido em momentos históricos, "o novo paradigma da tecnologia da informação fornece a base material para sua expansão penetrante em toda a estrutura social” (CASTELLS, 2002, p. $565)$.

Assim, a rede desempenha um papel central na era da informação.

Rede é muito mais do que interligação entre as diferentes tecnologias ou computadores. Redes são "articulações gigantescas entre pessoas conectadas com os mais diferenciados objetivos", sendo a internet o ponto central e dispersante de todas as conexões. "Chamada de rede das redes, a internet é o espaço possível de integração e articulação de todas as pessoas conectadas com tudo o que existe no espaço digital, o ciberespaço" (KENSKI, 2007, p.34).

Sendo assim, as TIC's podem favorecer o cumprimento das principais funções do Estado, alterando o tratamento da gestão pública no sentido de tornar mais acessível ao cidadão, empresas e outras organizações os serviços públicos.

Portanto, a fim de favorecer a governança, uma das possibilidades é a utilização das tecnologias de informação e comunicação (TIC's) pelo próprio governo. 
Para refletir acerca desta possibilidade, primeiramente se estabelecerá a conceituação de governo eletrônico, para então tratar da governança eletrônica, também os relacionando entre si.

\subsection{Governo Eletrônico}

Governo eletrônico (ou e-governo, ou e-gov) pode ser resumido pelo "acesso via internet a informações e serviços oferecidos pelos governos", tanto no sentido de oferta quanto de troca, para cidadãos, empresas, organizações variadas e outras agências governamentais (GUIMARÃES e MEDEIROS, 2005, p. 2).

Para a ONU (2008, p. xvi), o governo eletrônico surgiu como um conceito multifacetado ligado à integração vertical e horizontal de governo tanto a nível local, nacional e transnacional.

Teria três diferentes focos: a) melhorar o acesso e a prestação de serviços - informações integradas, novos mecanismos de feedback, consultas e formas mais participativas de democracia; b) gestão e prestação de administração pública - visando reduzir os custos e melhorar a eficácia e a eficiência das funções de base do governo; c) a remoção das barreiras à cooperação e desenvolvimento internacional e criando uma agenda de governação conectada globalmente, para aqueles que trabalham a nível transnacional (ONU, 2008, p. xvii).

Dentro desse contexto,

"o governo eletrônico foi visto como uma oportunidade de incrementar a participação da sociedade na gestão pública, especialmente quanto à formulação, ao acompanhamento e à avaliação das políticas públicas, visando ao incremento da cidadania e da democracia. O e-gov teria, então, um papel de destaque a cumprir na forma do governo interagir com os cidadãos e as organizações, não somente pela disponibilização de informações e serviços, mas ao levar em conta o potencial dos meios eletrônicos para a construção da governança eletrônica" (GUIMARÃES e MEDEIROS, 2005, p. 14). 
Assim, uma adequada implantação do governo eletrônico termina por ser, de certa forma, imprescindível para o desenvolvimento da governança eletrônica, como melhor se verá no item a seguir.

\title{
3.2 Governança Eletrônica
}

No contexto de utilização das TIC's para gestão pública pelas instituições governamentais, pode-se entender a governança eletrônica (ou e-governança) como o procedimento que visa a "manifestação política e a participação da sociedade civil, junto ao governo, por meios eletrônicos, na formulação, acompanhamento da implementação e avaliação das políticas públicas, com vista ao desenvolvimento da cidadania e da democracia" (GUIMARÃES E MEDEIROS, 2005, p. 6).

Um dos principais pontos para se entender a magnitude da utilização das TIC's como forma de favorecimento da governança é a facilidade que elas geram na "união dos cidadãos, pessoas-chave e representantes legais para participarem das comunidades, junto ao governo, por meios eletrônicos" (FERGUSON, 2002 apud GUIMARÃES E MEDEIROS, 2005, p. 6)

As TIC's que proporcionam um acesso instantâneo a dados, serviços e a comunicação com outros cidadãos, pois a web elimina qualquer distância.

Como ensinam Guimarães e Medeiros (2005, p. 2), a governança eletrônica é

\begin{abstract}
"o resultado da contribuição do e-gov para um contexto maior no qual o governo formula e implementa suas políticas com a participação da sociedade, considerando o papel das tecnologias de informação e comunicação e o ambiente regulatório que determina a atuação dos diversos atores".
\end{abstract}

A governança eletrônica funciona como uma rede de políticas de dentro e fora do governo, para a realização de políticas públicas (LÖGFREN, 2007, p. 336).

Pensando em governança, há a superação do tradicional conceito hierárquico de governo, que coloca um Estado central e unitário no centro da política pública - a tendência é a superação do modelo linear de realização de políticas, para algo mais fluido e flexível, com avaliações e aprimoramentos em todos os estágios do policy cycle, possibilitando inclusive alteração na agenda governamental (LÖGFREN, 2007, p. 338). 


\subsection{Exemplos Práticos de E-Governo e E-Governança}

No Brasil, o primeiro passo institucional para a implantação do governo eletrônico se deu com a entrada em vigor do Decreto Presidencial de 03/04/2000, através do qual se criou um Grupo de Trabalho Interministerial para propor novas formas eletrônicas de informação (GT Tecnologia da Informação). Já em outubro do ano 2000, foi criado o CEGE (Comitê Executivo do Governo Eletrônico), coordenado pela Casa Civil. Por este Comitê, foi proposta a Política de Governo Eletrônico para o Poder Executivo Federal (GUIMARÃES e MEDEIROS, 2005, p. 3).

As duas vertentes para a mencionada Política eram as diretrizes do CEGE somadas com a "universalização de serviços para a cidadania", "governo ao alcance de todos" e "infraestrutura avançada e novos serviços", ou seja, 3 das 7 linhas de ação do Programa SocInfo, do Ministério da Ciência e Tecnologia, parte do plano plurianual 2000-03 e 2004-07, o qual tinha como objetivo incluir o Brasil na sociedade de informação (GUIMARÃES e MEDEIROS, 2005, p. 3).

Por outro lado, a fim de facilitar a visualização do que se sugere como governança a partir da utilização das TIC's no governo eletrônico, opta-se por utilizar o caso sueco, o qual, já está bem avançado neste quesito.

A Suécia já possui um modelo dualista de serviço civil na administração pública: as diferentes agências governamentais são gerenciadas independentemente por uma gestão de execução, com bastante autonomia em face ao governo, devendo tão somente cumprir suas pretensões dentro dos limites de suas abrangentes instruções (LÖGFREN, 2007, p. 340).

Mesmo com esta diferente forma de administração púbica, desde a década de 60 já se fala em implementação de tecnologias para a facilitação da gestão pública. Contudo, somente em 1997 promulgou-se uma Lei prescrevendo a importância da exploração de novas TIC's para a modernização da administração governamental, buscando maior eficiência (LÖGFREN, 2007, p. 340).

Em 1999, assim, foi instituída a Swedish Agency for Public Managment (SAFAD), a qual criou e implementou a Agency 24/7 (LÖGFREN, 2007, p. 342).

A 24/7 Agency objetiva o desenvolvimento de uma administração pública que interliga as autoridades governamentais e os governos locais e regionais de forma a 
colaborar em redes e cumprir seus deveres, permitindo aos cidadãos e às empresas participarem: é a reinvenção de administração central para uma administração em rede um exemplo de governança instituída eletronicamente.

\subsection{Governança Eletrônica como uma Decorrência de um E-Gov bem Desenvolvido}

Em estudo realizado pela ONU, a fim de estimular a governança conectada a partir da desenvoltura do e-gov, foram expostos três critérios de avaliação, os quais são entendidos inclusive como fases essenciais para um governo eletrônico eficaz e hábil a promover a e- governança.

São eles: a) infraestrutura - a criação de uma estrutura de informação tanto para o setor público quanto para a sociedade em um geral, baseada em uma confiável e acessível conexão de internet para os cidadãos, comerciantes e todos os atores dentro daquela jurisdição; b) integração - elevar esta nova estrutura dentro do setor público visando um melhor compartilhamento de informações (interna e externamente) e unindo, integrando e prestando serviços de forma mais eficiente e em modelos de governança centrados no cidadão; c) transformação - buscando inovação em serviços e um e-gov que abranja toda a comunidade e pretenda o desenvolvimento democrático através de padrões de governança em rede, através de vários níveis de governo e todos os setores abrangidos por aquele sistema (ONU, 2008, p. 78-79).

A partir daí se verifica como a governança eletrônica deve ser precedida de um governo eletrônico bem estruturado.

\section{A INTERNET ENQUANTO TIC E A GOVERNANÇA}

Após analisado o que se pretende com a governança, em especial frisando a necessidade de uma gestão inclusiva, a qual deve estimular a participação política e o debate horizontalmente no momento das tomadas das decisões públicas, importante ressaltar a importância de se pesquisarem as ferramentas já havidas e se desenvolverem e utilizarem novas formas de desenvolvê-la. 
Como ensina Castells $(2004,188)$, em um mundo em que a crise de legitimidade política e a descrença dos cidadãos nos seus representantes, considerando o grande potencial que a internet tem de proporcionar "um canal interativo e multidirecionado", não se tem visto uma utilização muito promissora. Para ele, "a internet cumpre um papel fundamental na nova dinâmica política", caracterizada pelo que denomina de "política informacional", eis que a comunicação a partir dos governos sem embasa, principalmente, na política que se dá através dos meios de comunicação e em sistemas de informação.

O que se tem visto, assim, é que, ao invés de favorecer e aprimorar a democracia através da ampliação dos canais de informação e participação dos cidadãos, a utilização da internet tem tendido a piorar a crise de legitimidade política. Por obvio, o problema não é a internet, mas sim o tipo de política que as nossas sociedades estão a gerar" (CASTELLS, 2004, 190).

O que se tem visto é que os governos, em todos os níveis, têm empregado a internet como meio de publicidade para divulgar algumas restritas informações, não disponibilizando possibilidades reais de interação com os cidadãos. Inclusive, "os representantes parlamentares muitas vezes têm os seus próprios websites mas não lhes prestam demasiada atenção, nem no desenho nem nas respostas às petições dos cidadãos”. (CASTELLS, 2004, 186-187).

Contudo, analisando a internet e as TIC's, percebe-se que oferecem

\footnotetext{
"um potencial extraordinário para a expressão dos direitos do cidadão e para a comunicação dos valores humanos. Obviamente, não pode substituir a mudança social ou a reforma política. No entanto, ao igualar relativamente as condições nas quais os distintos atores e instituições podem agir com a manipulação de símbolos, e ao ampliar as fontes de comunicação, contribui sem dúvida para a democratização. A internet põe em contato as pessoas na ágora pública, permitindo-lhes expressar as suas preocupações e partilhar as suas esperanças. Por isso, o controle dessa ágora pública por parte das pessoas talvez

seja o desafio político mais importante que a internet apresenta" (CASTELLS, 2004, 197).
}

Estes meios de comunicação e informação em redes, quais sejam através da internet, tem o condão de facilitar o acesso à informação política, possibilitando que 
os cidadãos estejam amplamente informados quanto às ações e decisões de seus representantes. Todavia, isso depende da "boa vontade do governo", pois a este cumpre a disponibilização online de todos os documentos oficiais e não confidenciais (CASTELLS, 2004, p. 186).

Da mesma forma, a interatividade que o emprego de TIC's pode proporcionar permite que os cidadãos se manifestem e solicitem posicionamentos de seus governantes, demandando uma resposta "personalizada". Neste sentido, "as pessoas poderiam vigiar o seu governo, algo a que deveriam ter direito, já que, em teoria o poder reside no povo. No entanto, a maior parte dos estudos e relatórios descrevem um panorama bastante negativo, com a possível exceção das democracias escandinavas”. (CASTELLS, 2004, p. 186).

De t od a s orte, indubitavelmente a internet pode proporcionar "um canal de comunicação horizontal, não controlado e relativamente econômico, de um para um e de um para muitos". Há uma grande capacidade desta TIC de se transformar em um meio essencial para a expressão popular e organização de manifestações públicas, por exemplo (CASTELLS,

2004, p. 168). Neste sentido, “a internet proporciona a base material que permite a estes movimentos mobilizarem-se na construção de uma nova sociedade" (CASTELLS, 2004, 168-

169).

Como ensina Egler (in EGLER (org.), 2007, p. 176)

\begin{abstract}
"as novas tecnologias permitem formas de organização inovadoras e horizontais entre as partes e o todo. São muitos grupos que podem se conectar entre si e constituir novas totalidades, de forma que a totalidade se reproduz dentro das partes, como uma forma orgânica, em que todas as células reproduzem a totalidade dos elementos que compõem o corpo das organizações governamentais de gestão da cidade. Essa possibilidade é pouco percebida pelas instituições governamentais, que reproduzem formas de organização burocráticas, verticalizadas, e definem as relações de poder tradicionais das instituições governamentais.

O uso de novas tecnologias não altera as práticas políticas na máquina burocrática, quando o Estado assume para si a responsabilidade de dar a solução, e o cidadão é o demandante do processo. O que nos preocupa é o papel ativo que cada um desempenha na administração da vida cotidiana. O que se
\end{abstract}


quer demonstrar é que, mesmo com a existência de canais de comunicação, o sujeito da enunciação permanece sendo o Estado. Trata-se de uma relação em que o cidadão demanda e o Estado atende à solicitação formulada".

Isso demonstra como, do mesmo modo antes expresso por Castells, deve haver interesse e mobilização dos representantes políticos em implementar políticas públicas de inclusão digital e coordenar a criação de mecanismos de aplicação de TIC's para a gestão pública e participação cidadã.

A coordenação mencionada é essencial para a integrar os mais diversos níves de governo "com outras organizações, incluindo o setor privado. Não só a competência gerencial mas também a habilidades políticas são necessárias para a construção de estruturas e serviços de informação adequados e para a manutenção de uma visão de longo termo" (ZUGMAN, 2006, p. 47).

Muitas são as possibilidades de TIC's aplicáveis para estes fins. Contudo, este artigo opta por ponderar acerca de somente uma, qual seja a implantação de cidades digitais, verificando suas contribuições para a gestão pública e a viabilidade de ser utilizada como um meio facilitador de governança.

\section{CIDADES DIGITAIS}

Castells (2004, p. 180) ensina que "as origens da cidade digital são significativas, tanto por questões analíticas quanto pelo seu desenvolvimento posterior". Para ele, as origens estão nas redes de cidadania europeias, as quais, por sua vez, vêm dos movimentos contraculturais e na cultura hacker ${ }^{2}$. Contudo, ele demonstra como estes antecedentes também servem para representar como as redes de cidadania, para "chegar a uma base de utilização mais ampla dependem, em grande medida, do apoio institucional de uma administração com mente aberta, apesar da divergência de objetivos”.

\subsection{Conceituando Cidades Digitais}

Cidades digitais são redes de pessoas e das mais diversas instituições, as quais se conectam a uma infraestrutura de comunicação digital pela qual é possível a utilização da 
2 A cultura hacker surgiu no "âmbito universitário, através da inspiração dos investigadores acadêmicos e também como expressão política dos estudantes” (CASTELLS, 2004, p. 180).

cidade física como referência visando o desenvolvimento das relações sociais. Isto inclui espaços políticos e culturais para a manifestação de pessoas ou grupos, canais de comunicação e negociação entre governos municipais e a população, maior identificação dos visitantes com a cidade de referência e banco de dados com informações sobre a cidade de referência (ZANCHETI, 2001, p. 313).

Cidades digitais podem servir como um ambiente de aplicação de infraestrutura de comunicação e serviços para melhorar o diálogo entre munícipes e o governo local, estimulando muitas atividades que promovam oportunidades aos cidadãos (GRAHAM, 1996, p. 2).

Essas cidades funcionam como ferramenta política para uma variedade de planos urbanísticos e assim, como definidas por Graham (1996, p. 24):

\begin{abstract}
"as cidades virtuais são espaços eletrônicos, em geral com base na World Wide Web, que foram desenvolvidos para interligar, de forma explícita, as agendas de desenvolvimento de cada cidade. Tais cidades virtuais estão funcionando como ferramenta política para uma variedade de planos e objetivos urbanos: marketing urbano global, estímulo ao turismo de negócios e de consumo, melhoria das comunicações entre os cidadãos e os governos locais, aumento da competitividade das empresas locais, maior integração das economias locais e o renascimento do civismo e da cultura local".
\end{abstract}

O interessante é que, mesmo que esses sistemas ofereçam acesso aos mais variados serviços da internet, "sua ênfase principal reside nas discussões locais, nas interações e nos serviços de informação que inserem os cidadãos em suas próprias cidades" (GRAHAM, 1996 ,

p. 24).

Assim, as cidades digitais apresentam as mais variadas facetas, eis que combinam atividades políticas, econômicas e sociais (CAIRE, 2009, p. 4).

As cidades digitais podem promover as e-administrações e os e-governos, bem como contendo ferramentas para melhorar a democracia e a participação local, fornecendo infraestruturas locais de informação sociais sobre a cidade real com serviços públicos e 
administrativos para os cidadãos e visitantes. Aqui, as atividades são predominantemente políticas e, em menor medida, econômicas e sociais. Da mesma forma, podem conter os portais de e-comércio, ou seja, fornecer recursos práticos de fácil acesso a informação que ajudam na organização do cotidiano. São atividades predominantemente econômicas, como serviços comerciais, de compras e entretenimento. Enfim, contem também mundos sociais virtuais, cujas atividades são predominantemente de relações sociais, as quais, por sua vez, atraem anunciantes e empresas devido a quantidade de usuários (CAIRE, 2009, p. 4-5).

Pelo que se verifica, a cidade digital pode manifestar atividades tanto públicas quanto comerciais. A diferença está nos objetivos: enquanto as públicas voltam-se para a busca de lucro, para mercados verticais (compras, entretenimento etc) e para receitas geradas por publicidade, as públicas não visam lucro, voltam-se para um governo eficiente e acessível, aceleram o desenvolvimento econômico e buscam a melhoria da democracia (CAIRE, 2009, p. 7).

\subsection{A Implantação de Cidades Digitais}

Muitos têm sido os acadêmicos que vêm estudando as cidades digitais, a fim de encontrar suportes para as decisões neste tipo de emprego de TIC. Por exemplo, Ergazakis et. al. (2011, p. 149), considerando que o gerenciamento de conhecimento é um recurso estratégico para uma aplicação das cidades digitais, ensinam que o "Desenvolvimento Baseado em Conhecimento" tem sido utilizado por cidades e regiões com alta penetrabilidade de serviços de TICs, na forma de cidades digitais.

Eles ensinam que a adoção dessas estratégias proporciona a melhora da vida cotidiana, o reforço da participação cidadão nos processos de tomada de decisão, o incentivo ao empreendedorismo e inovação, bem como apoio aos processos de gestão do conhecimento na região (ERGAZAKIS et. al., p. 149).

Quanto as expectativas da administração pública em um contexto de disponibilidade de TICs, aplicando por exemplo as cidades digitais, eles mostraram que concernem, em regra, prover acesso a internet de alta velocidade a baixos custos, diminuir os custos de operações administrativas, aumentar a segurança, aumentar a competitividade 
econômica e aumentar a qualidade de vida e a satisfação do cidadão (ERGAZAKIS et. al., p. 150).

Contribuindo para as implementações de cidades digitais, identificaram sete estágios para provisão e manutenção de serviços e aplicações digitais: a) identificar o principal grupo de ação; b) encontrar os provedores de tecnologia; c) elaborar um modelo de negócios; d) construir um consenso comunitário; e) localizar fontes de recursos; f) explorar oportunidades de parceria; e g) estabelecer um modelo de gestão (ERGAZAKIS et. al., p. 150-151).

Os pesquisadores Ergazakis et. al. (2011, p. 151) sugerem, para implantação de cidades digitais em países em desenvolvimento, que comecem como projeto piloto, o qual deve justificar seu investimento inicial no fato de gerar economia e maior eficiência na administração pública, substituir um sistema ou uma infraestrutura defasada, promover desenvolvimento econômico e aumentar a satisfação dos cidadãos através de provisão de serviços de internet de alta velocidade a comunidades isoladas ou de baixa renda.

Dentre os inúmeros benefícios, está a eficiência na gestão pública, decorrente da eficiência nas operações dos serviços públicos. Disto decorre uma maior satisfação dos cidadãos, os quais passam a recuperar a confiança nos seus administradores.

Ademais, a implantação deste tipo de TIC, disponibilizando um acesso em rede às mais variadas funções de uma cidade, permite um acréscimo no desenvolvimento econômico local.

Como um dos aspectos envolvendo as cidades digitais está na disponibilização de tecnologia para os cidadãos, há uma consequente minoração no abismo digital entre certas camadas da sociedade. Em regra, centrais de computadores são disponibilizadas aos cidadãos, os quais podem usufruir dos serviços e serem digitalmente incluídos.

São muitos os casos de implantação bem sucedida de cidades digitais. Ergazakis et. al. (2011, p. 152-154) citam Issy-les-Moulieneaux, na França e Tampere, na Finlândia. Ambas foram muito bem sucedidas, se tornando exemplos de aplicação de TIC na gestão pública.

Pazalos et. al. (2012, p. 123-124), por sua vez, demonstram como os e-serviços são cruciais na exploração destas caras infraestruturas de rede como as cidades digitais, já que se não teriam valor caso não fossem utilizadas dessa forma. Os e-serviços são, 
atualmente, subutilizados, portanto é importante a sua avaliação para o entendimento de suas potencialidades e fraquezas. Eles afirmam que os e-serviços nas cidades digitais contribuem para a economia dos gastos públicos, proporcionando assim um aprimoramento na gestão e uma possibilidade de maiores investimentos nestas tecnologias.

Analisando os agentes cooperativos de informação, no âmbito das cidades digitais, Oyama et. al. (2001, p. 1-2) demonstram como, sendo uma tecnologia em rede, que facilita uma troca horizontal de informações e comunicação, há uma contribuição mútua entre o público e o privado, a comunidade e o mercado, o administrador e o cidadão, a fim de manter o bom funcionamento daquele sistema.

Para tanto, exemplificam a cidade digital de Kyoto, a qual se distingue por sua característica conexão com a cidade física, sendo uma cidade "viva", que possui integração dinâmica com a web e sensores em tempo real. Esta cidade é tão complexa que demanda agentes que atuam tanto na mediação com o usuário quanto aqueles que organizam a informação total disponível.

A complexidade de uma estrutura como a cidade digital é imensa, mas não difere da estrutura de uma cidade real. O que as diferencia está na facilidade de acesso aos seus mais variados aspectos e serviços.

As mais aparentes contribuições da cidade digital estão na prestação de serviços a toda comunidade e na inclusão digital.

De fato, pode ser que haja mais do que isso. As cidades digitais também permitem o estímulo de interações sociais e políticas, dentro de um espaço concentrado.

Contudo, pelo que se verificou neste estudo, considerando os casos práticos já existentes, em regra as cidades digitais são utilizadas para otimizar o e-governo e aproximar os indivíduos dos serviços ofertados por uma cidade.

Caso haja interesse, os governos e os implantadores das cidades digitais podem utilizar desta ferramenta como uma forma de governança, eis que há viabilidade para este contato cidadão-gestor. Entretanto, ainda não se verificou tal façanha.

As possibilidades das redes são muitas, basta haver interesse e ação. Como ensina Castells (2004, p. 278), “a geografia das redes é uma geografia de inclusão e exclusão, que depende do valorque os interesses socialmente dominantes outorguem a um lugar determinado". 


\section{CONCLUSÃO}

No decorrer do presente artigo, identificou-se a crise envolvendo as democracias contemporâneas, sugerindo que o estímulo da governança como forma complementar e, talvez, até alternativa ao governo tradicional poderia auxiliar na retomada da confiança dos cidadãos nos seus governantes.

Como forma de exercício de governança, sugeriu-se a utilização das TIC's para o favorecimento da governança, facilitando o diálogo entre os governados e seus representantes, em especial trabalhando a relação entre essa - enquanto governança eletrônica - e o próprio governo que se utiliza das TIC's - ou e-gov.

Ao aprofundar mais a temática, tratou-se da relação entre internet e as possibilidades de facilitação da governança.

E, então, foram elencadas as cidades digitais como TIC's que utilizam se manifestam por internet, investigando quais os aspectos que as envolvem e procurando identificar se elas podem contribuir para o exercício da governança.

Conclui-se que as cidades digitais possuem potencial para serem espaços depromoção da governança, através da comunicação dos cidadãos com os tomadores de decisão para uma atuação conjunta e uma gestão compartilhada do público.

Contudo, ainda não há evidências conclusivas de que isso já ocorreu, tendo em vista que as pesquisas sobre o tema demonstram grande eficácia das cidades digitais para outros fins, tais como prestação de serviços e inclusão digital.

Portanto, sugere-se que a presente pesquisa sirva de estímulo para investigações futuras acerca das cidades digitais e sua relação com a governança, procurando demonstrar através de novos estudos de caso se já há resultados no sentido de sua promoção.

\section{REFERÊNCIAS}

AZEVEDO, Sérgio de; ANASTASIA, Fátima. Governança, “accountability” e responsividade. Revista de Economia Política, v. 22, n. 1, jan./mar. 2002.

BOBBIO, Norberto. Futuro da democracia. 7. ed. São Paulo: Paz e Terra, 2000. 
BROWN, Mary Maureen. Understanding e-government benefits: an examination of leadingedge local governments. The American Review of Public Administration, v. 37, n. 2, p. 178-197, 2007. Disponível em < http://arp.sagepub.com/content/37/2/178.short>. Acesso em: 24 jul. 2015.

CAIRE, Patrice. Designing convivial digital cities: a social intelligence design approach. AI \& Society, London, v. 29, n. 1, 2009. Disponível em <http://link. springer.com/article/10.1007\%2Fs00146-009-0201-x\#page-1>. Acesso em: 23 jul. 2015.

CANET, Raphaël. Qu'est-ce que la gouvernance? Conférences de la Chaire MCD, 2004. Disponível em <http://er.uqam.ca/nobel/ieim/IMG/pdf/canet-mars-2004.pdf>. Acesso em: 29 jul. 2015.

CASTELLS, Manuel. A era da informação: economia, sociedade e cultura. Volume 1: A sociedade em rede. 6. ed. São Paulo: Paz e Terra, 2002.

A galáxia da internet: reflexões sobre internet, negócios e sociedade. Lisboa: Fundação Calouste Gulbenkian, 2004.

DOUKAS, C.; METSIS, V.; BECKER, E.; LE, Z.; MAKEDON, F.; MAGLOGIANNIS, I. Digital cities of the future: extending @ home assistive technologies for the elderly and the disabled. Telematics and Informatics, v. 28, n. 3, p. 176-190, ago.2011. Disponível em < http://www.sciencedirect.com/science/article/pii/S073658531000050X>. Acesso em: 25 jul. 2015.

EGLER, Tamara Tania Cohen. A ação política dos atores em rede no governo da cidade. In: EGLER, Tamara Tania Cohen (org.). Ciberpólis: redes no governo da cidade. Rio de Janeiro: 7Letras, 2007.

ERGAZAKIS, E.; ERGAZAKIS, K.; DIMITRIOS, A.; CHARALABIDIS, Y. Digital cities: towards an integrated decision support methodology. Telematics and informatics, v. 28, n. 1, ago. 2011. Disponível em < http://www.sciencedirect.com/science? $\mathrm{ob}=$ ArticleListURL\&_method=list\&_ArticleListID=-838848395\&_sort=r\&_st=13\&view=c\& md5=78a4d1 f9f5b0f5316048f0a543acda88\&searchtype=a>. Acesso em 24 jul. 2015.

GRAHAM, Stephen. Rumo à cidade em tempo real: desenvolvimento urbano numa sociedade globalizada e telemediática. In: GRAHAM, Stephen; MARVIN, Simon. Telecommunications and the city: electronic spaces, urban spaces. London: Routledge,

1996. Disponível em <http://www.wisetel.com.br/espaco_de_futuros/vcidade.htm>. Acesso em: 23 jul. 2015.

GUIMARÃES, Tomás de Aquino; MEDEIROS, Paulo Henrique Ramos. A relação entre governo eletrônico e governança eletrônica no governo federal brasileiro. Cadernos EBAPE.BR, v. 3, n. 4, Rio de Janeiro, dez. 2005. Disponível em < http://www. scielo.br/scielo.php?pid=S167939512005000400004\&script=sci_arttext $>$. Acesso em: 24 jul.

2015.

HAQUE, S.; MEMON, R.A.; SHAIKH, A.. E-government using grid technology: developing a grid framework for $\mathrm{G} 2 \mathrm{G}$ e-communication and collaboration system. International Journal of Independent Research and Studies - IJIRS, v. 2, n. 1, p. 08-15, jan. 2013. Disponível em < http://pakacademicsearch.com/pdf-files/art/68/8-15\%20Vol.\%202,\% 
20No.1\%20(January,\%202013).pdf>. Acesso em: 24 jul. 2015.

KENSKI, Vani Moreira. Educação e tecnologias: O novo ritmo da informação. Campinas: Papirus, 2007.

LEFORT, Claude. Pensando o político: ensaios sobre democracia, revolução e liberdade. São Paulo: Paz e Terra, 1991.

LÖGFREN, Karl. The governance of e-government: a governance perspective on the swedish egovernment strategy. Public Policy and Administration, v. 22, n. 3, p. 335-352, 2007. Disponível em < http://www.business-anti-corruption.com/media/3831411/The_Governance_ of_e-government.pdf $>$. Acesso em: 24 jul. 2015.

MALLOY, James. Política Econômica e o Problema da Governabilidade nos Andes Centrais. In: SOLA, L. (Org.). Estado, Mercado e Democracia: Política e Economia Comparada. São Paulo: Paz e Terra, 1993. Apud: SANTOS, Maria Helena de Castro. Governabilidade, Governança e Democracia: criação de capacidade governativa e relações executivo-legislativo no Brasil pós-constituinte. Dados, v. 40, n. 3, Rio de Janeiro, 1997. Disponível em < http://www.scielo.br/scielo.php? script=sci_arttext\&pid=S001152581997000300003>. Acesso em: 25 jul. 2015.

NAÇÕES UNIDAS. A ONU e a governança. 2009. Disponível em $<$ http://www.onu.org.br/a-onu-em-acao/a-onu-em-acao/a-onu-e-a-governanca/>. Acesso em: 25 jul. 2015.

. United Nations e-government survey 2008: from e-government to connected governance. New York, 2008. Disponível em <http://unpan3.un.org/ egovkb/portals/egovkb/Documents/un/2008-Survey/unpan028607.pdf>. Acesso em: 25 jul. 2015.

OYAMA, S.; HIRAMATSU, K.; ISHIDA, T.. Cooperative information agentes for digital cities. International Journal of Cooperative Information Systems, v. 10, n. 2, mar.-jun. 2001. Disponível em < http://www.worldscientific.com/doi/pdf/10.1142/S0218843001000 $31 \mathrm{X}>$. Acesso em: 27 jul. 2015.

PAZALOS, K.; LOUKIS, E.; NIKOLOPOULOS, V.. A structured methodology for assessing and improving e-services in digital cities. Telematics and Informmatics, v. 29, n. 1, p. 123 -

136, fev. 2012. Disponível em <http://www.sciencedirect.com/science/article/pii/S 073658531000033X>. Acesso em: 24 jul. 2015.

ROSNEAU, James N. Governança, ordem e transformação na política mundial. In: ROSNEAU, James N.; CZEMPIEL, Ernest-Otto (Org.). Governança sem governo: ordem e transformação na política mundial. Brasília: Editora UnB, 2000. Disponível em < http ://www.fflch.usp.br/dcp/assets/docs/BibliografiaSelecaoPos/ROSENAU_2000.pdf>. Acesso em: 25 jul. 2015.

SANTOS, Maria Helena de Castro. Governabilidade, Governança e Democracia: criação de capacidade governativa e relações executivo-legislativo no Brasil pós-constituinte. Dados, v. 40, n. 3, Rio de Janeiro, 1997. Disponível em < http://www.scielo.br/scielo.php? script=sci_arttext\&pid=S0011-52581997000300003 $>$. Acesso em: 25 jul. 2015. 
SILVA, Daniel José da. Desafios sociais da gestão integrada de bacias hidrográficas: uma introdução ao conceito de governança da água. 740 Congréss de L'ACFAS, Université MacGill. Montreal, 2006. Disponível em <http://www.gthidro.ufsc.br/arquivos/acfas_ governanca.pdf>. Acesso em: 24 jul. 2015.

ZANCHETI, Sílvio Mendes. Cidades Digitais e o desenvolvimento local. Revista de Ciência e Tecnologia - RECITEC, Recife, v.5, n.2, p.311-329, 2001. Disponível em < https://docs.google.com/file/d/0B9zr_v5XGE7HWFI3eDFtNkVDRlU/edit>. Acesso em: 27 jul. 2015.

ZUGMAN, Fabio. Governo eletrônico: saiba tudo sobre essa revolução. São Paulo: Livro Pronto, 2006. 